\title{
AS FUNÇÕES DA EDUCAÇÃO AMBIENTAL NA EFETIVIDADE DE POLÍTICAS AMBIENTAIS MARINHAS E COSTEIRAS NO BRASIL
}

Tális Pereira Matias ${ }^{1}$

Adriana Maria Imperador ${ }^{2}$

Resumo: Ecossistemas marinhos e ambientes costeiros são amparados por leis específicas que demandam ações complementares como fiscalização e Educação Ambiental para a efetividade de muitos aspectos abordados por estas bases jurídicas. Desta forma, este trabalho objetiva a avaliação das funções e proposições de alternativas de Educação Ambiental para a eficácia de Políticas Ambientais Marinhas e Costeiras (PAMC). A metodologia utilizada foi qualitativa, buscando informações em decretos, leis e artigos científicos. Dentre os principais resultados destaca-se o potencial e funções da Educação Ambiental para a conquista de objetivos conservacionistas e sustentáveis associados às PAMC no Brasil.

Palavras-chave: Meio Ambiente; Sustentabilidade; Conservação; Direito Ambiental; Impactos Ambientais.

Abstract: Marine ecosystems and coastal environments are supported by specific laws that demand complementary actions such as inspection and Environmental Education for the effectiveness of many aspects addressed by these legal bases. Thus, this research aims to evaluate the functions and propositions of alternatives in Environmental Education for the effectiveness of Marine and Coastal Environmental Policies (MCEP). The methodology used was qualitative, seeking information in decrees, laws and scientific articles. Among the main results, the potential and functions of Environmental Education for achieving conservation and sustainable goals associated with MCEP in Brazil stand out.

Keywords: Environment; Sustainability; Conservation; Environmental Law; Environmental impacts.

\footnotetext{
1Universidade Federal de Alfenas. E-mail: talismatias12@gmail.com, Link para o Lattes: http://lattes.cnpq.br/2551120681904657

2Universidade Federal de Alfenas. E-mail: adriana.imperador@unifal-mg.edu.br. Link para o Lattes: http://lattes.cnpq.br/6511962778909776
} 


\section{Introdução}

O oceano é assunto de interesse global, é um ambiente heterogêneo, fundamental para a manutenção da vida na Terra e presta serviços ecossistêmicos fundamentais, além de abrigar ampla biodiversidade (HATJE; DA CUNHA; DA COSTA, 2013). Todavia, em função de atividades antrópicas, estes ambientes vêm sendo altamente impactados, trazendo prejuízos ambientais, sociais e econômicos, o que frisa a importância de ações participativas e inclusivas de Educação Ambiental (IMENIS BARRADAS, 2020).

Neste cenário, o conhecimento sobre a legislação vigente, ações do poder público e contribuição social são essenciais, assim como a avaliação de medidas adotadas para a mitigação de impactos ambientais negativos nestes ambientes. Para isso, a legislação específica de conservação do mar e outras políticas ambientais são fundamentais.

Muitas ações podem minimizar os impactos ambientais negativos no oceano, como a redução de poluição continental, hídrica, atmosférica, marinha e costeira, assim como a redução, reciclagem e reutilização de resíduos sólidos, como os de origem comercial, residencial, agrícolas e industriais. Entretanto, não basta a existência de leis, normas e políticas públicas, é preciso mais, é necessário fiscalização, gestão integrada, conscientização e sensibilização (COSTANZA, 1999; FRANCESCHI et al., 2017; SILVA; CHAVES; GHISOLFI, 2016).

Nestes quesitos, a Educação Ambiental possui um arcabouço forte de metodologias e atividades para a promoção de ações mais conscientes e sustentáveis (FIALHO; CUNHA, 2018). Como a própria Política Nacional de Educação Ambiental (lei no 9.795, de 27 de abril de 1999) dispõe, é por meio dela que o indivíduo e a coletividade constroem valores sociais voltados para a conservação do meio ambiente (BRASIL, 1999).

Considerando estes aspectos, o presente trabalho tem como objetivo a avaliação das principais funções da Educação Ambiental para a efetivação de Políticas Ambientais Marinhas e Costeiras (PAMC) e a indicação de propostas de ações participativas e interdisciplinares para a promoção da sustentabilidade e Educação Ambiental sobre os ecossistemas marinhos e costeiros.

\section{Metodologia}

A metodologia de pesquisa adotada neste trabalho provém de revisão bibliográfica qualitativa com foco sobre o método funcionalista e dialético. $O$ método funcionalista visa o estudo social de um ponto de vista da função de suas unidades, considerando um sistema organizado de atividades, enquanto que o dialético penetra o mundo dos fenômenos e considera que os fatos não podem ser considerados fora de um contexto social (PEREIRA et al., 2018).

A ferramenta principal de busca, para a construção da narrativa, foi o 
encontrados com resultados relevantes para o tema da pesquisa, visando melhorar a compreensão geral sobre a problemática aqui proposta e as suas implicações. Desta forma, com destaque para as Políticas Ambientais Marinhas e Costeiras (PAMC) e Educação Ambiental, os métodos descritos se aplicaram ao contexto socioambiental que circunda estes dois assuntos.

Para este estudo, considerou-se como Políticas Ambientais Marinhas e Costeiras (PAMC), leis em que se podem extrair princípios de proteção dos recursos ambientais marinhos e costeiros. Foram adotadas perspectivas similares ao contexto de políticas de conservação do mar (MATIAS; IMPERADOR, 2021), seus recursos e principais áreas de influência.

Por meio da análise destas leis, decretos (BRASIL, 1981; BRASIL, 1988; BRASIL, BRASIL, 1994; BRASIL, 1995; BRASIL, 1999; BRASIL, 2005) e artigos ligados ao tema, foi possível elaborar uma discussão pautada na interdisciplinaridade e importância da Educação Ambiental para a efetivação de Políticas Ambientais Marinhas e Costeiras (PAMC), conservação ambiental e promoção da sustentabilidade.

O direcionamento dos métodos adotados iniciou-se com a leitura e interpretação da legislação marinha brasileira pertinente e de artigos científicos em revistas especializadas na temática proposta, visando destacar a importância de práticas de Educação Ambiental para a promoção de hábitos mais sustentáveis associados ao ambiente marinho e costeiro. Com isso podese elaborar um mapa conceitual, uma nuvem interdisciplinar e um quadro com atividades de Educação Ambiental aplicadas à problemática do oceano e às PAMC, incluindo uma discussão reflexiva sobre o assunto.

\section{Contextualização e Aspectos Históricos}

Ao longo do tempo, problemas sociais, ambientais e econômicos marcaram a história do desenvolvimento humano. A Revolução Industrial foi um dos grandes marcos, que acentuou desigualdades e impulsionou a crise ambiental, associada ao crescimento populacional, exploração descontrolada dos recursos naturais e geração de poluição (VALERO; SANTIAGO; FRANÇA, 2019).

Segundo Barbosa e Aguiar (2018, p. 251),

(...) tratar de conservação em cenários onde a problemática ambiental se entrelaça a questões econômicas, sociais, culturais e políticas, a exemplo do que acontece em países em desenvolvimento como o Brasil, exige uma abordagem diferenciada e abrangente que considere ao máximo essa multiplicidade de fatores.

Ademais, os mesmos autores (2018, p. 251) ainda destacam que: 
(...) essa relação humano/natureza é instituída desde os primórdios da civilização, sua análise exige um recorte temporal mais amplo, uma vez que atuais circunstâncias socioambientais podem ter origem em eventos do passado.

A evolução brasileira conta com amplo histórico de degradação ambiental e perdas de serviços ecossistêmicos. O Brasil, com aproximadamente $11.000 \mathrm{~km}$ de costa, com uma zona costeira que se estende desde águas rasas até o oceano profundo, apresenta grande diversidade de ecossistemas e formações geomorfológicas suscetíveis à interferência antrópica (RIBEIRO et al., 2018), o que frisa a importância de Políticas Ambientais Marinhas e Costeiras (PAMC) eficazes.

Segundo Aslan, Pinto e Oliveira (2017, p. 183),

O crescimento populacional, associado ao desenvolvimento, a exploração dos recursos do mar e a crença na infinitude destes recursos pelo homem, tem alterado significativamente os níveis de poluição nos mares. A partir desta percepção, e ao reconhecer que o mar, por ser um recurso de uso comum, foram realizadas convenções e tratados internacionais ao longo dos últimos 50 anos na tentativa de criar mecanismos de controle e prevenção da poluição marinha. Neste contexto, o Brasil tem ampliado seu arcabouço jurídico, com leis e políticas públicas associadas a setores regulamentados.

Os desequilíbrios ecológicos, impactos ambientais e outros fenômenos decorrentes da falta de um desenvolvimento sustentável ao longo da história, além de impactos na saúde pública, foram fortes propulsores para debates e discussões que resultaram em grandes congressos, seminários e conferências internacionais, como Estocolmo (1972), Belgrado (1975), Tbilisi (1977), Moscou (1987), Eco 92 (1992) e Rio+20 (2012), em que o papel da Educação Ambiental ganha destaque para a contribuição das medidas de gestão e políticas adotadas por diversos países (BEZERRA, 2021).

\section{Educação Ambiental e Políticas Ambientais Marinhas e Costeiras (PAMC): conexões e funções}

As políticas nacionais de conservação do mar, assim como planos, documentos e outras formas de iniciativas públicas são medidas importantes para o alinhamento brasileiro ao contexto internacional, uma vez que traçam estratégias e normas específicas para a gestão marinha, conservação dos recursos do mar, segurança marítima e relações internacionais (BEIRÃO, 2019; BRASIL, 1988, 1994, 2005; BUEGER, 2015; MOREIRA, 2020; TRAJANO, 2010). 
No Brasil, para que ocorra a efetivação de aspectos conservacionistas destacados pela Política Nacional de Meio Ambiente (BRASIL, 1981) e pela Política Nacional para os Recursos do Mar (BRASIL, 2005), é necessário que haja participação e engajamento comunitário, visando o manejo adequado direto e indireto dos recursos marinhos e o desenvolvimento sustentável, o que frisa a função da Educação Ambiental neste aspecto (LAYRARGUES, 2020; SONG, 2015).

A Política Nacional para os Recursos do Mar (decreto № 5.377 de 23 de fevereiro de 2005) estabelece princípios e objetivos para a elaboração de planos, programas e ações de governo em formação de recursos humanos, desenvolvimento de pesquisa, ciência e tecnologia marinha, exploração e aproveitamento sustentável dos recursos do mar.

Dentre os princípios da política, destacam-se: a harmonização com as demais políticas, definições de prioridades voltadas à sustentabilidade, execução descentralizada e participativa, princípio da precaução, proteção da biodiversidade e do patrimônio genético de áreas sob a jurisdição nacional, além da observância dos compromissos internacionais assumidos pelo Brasil.

Para a garantia de certos atributos das PAMC estudadas, no que tange à sociedade e à responsabilidade coletiva, se faz necessário que a Educação Ambiental atue na promoção de uma nova cultura, na construção de valores sociais conservacionistas e na percepção do papel de cada indivíduo e da sua responsabilidade coletiva.

Desta forma, a Figura 1 mostra um mapa conceitual que ilustra as conexões principais entre a Educação Ambiental e as PAMC. Percebe-se que os processos de Educação Ambiental implicam em aspectos fundamentais para a prática das PAMC, e que em função disso, a interdisciplinaridade entre as duas partes deve ser fortalecida.

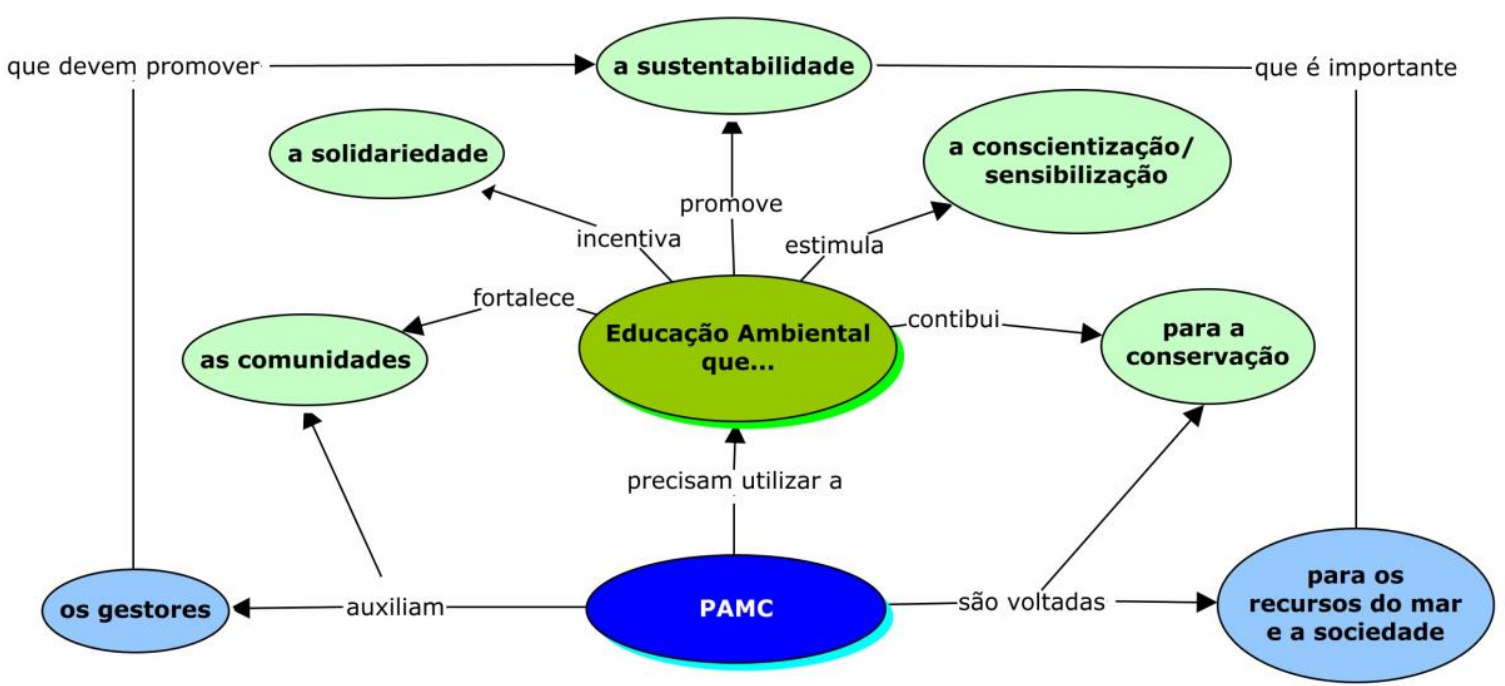

Figura 1: Mapa conceitual sobre as Políticas Ambientais Marinhas e Costeiras (PAMC) e a Educação Ambiental. Fonte: Dos autores. 
A análise da Figura 1 resulta do estudo sistemático da legislação específica sobre recursos do mar e da zona costeira (BRASIL, 1988, 1994, 1995, 2005) e Educação Ambiental (BRASIL, 1999). Tais aspetos evidenciam a importância e a função da Educação Ambiental como ferramenta transformadora de práticas lesivas aos ecossistemas marinhos e costeiros.

Destaca-se ainda que, praticar a Educação Ambiental no Brasil é um grande desafio, em diversos aspectos. Avanços e retrocessos na Política Nacional de Educação Ambiental são fatores que evidenciam esta realidade e mostram a importância de apoio público e processos independentes de Educação Ambiental, uma vez que diversas questões, como falta de investimentos públicos na área, afetam diretamente a implementação de políticas públicas no Brasil (GARCIA et al., 2020).

\section{A prática da Educação Ambiental como alternativa integradora para a efetividade de Políticas Ambientais Marinhas e Costeiras (PAMC)}

Diversos processos como a urbanização, modelos de produção, fluxo de produtos e serviços, além de outros fatores políticos, econômicos e culturais configuram um quadro complexo de ações que afetam os ambientes marinhos e costeiros (HATJE; DA CUNHA; DA COSTA, 2018; RIO, 2018; SILVA; CHAVES; GHISOLFI, 2016). Observa-se, neste sentido, que soluções interdisciplinares englobando, principalmente política e ciência, devem ser alavancas urgentes para a sustentabilidade (TELLES, 2018).

A percepção ambiental é um dos elementos relevantes para subsidiar decisões importantes e estratégias em Gestão Marinha e Costeira, uma vez que a percepção ambiental representa o modo pelo qual os indivíduos expressam o meio ao qual interagem, ficando notável a existência de relações benéficas ou nocivas ao meio ambiente e até mesmo para a própria comunidade (DE OLIVEIRA; DOS SANTOS; TURRA, 2018).

Desta forma, considerando os atributos da Educação Ambiental, percebe-se que este instrumento da Gestão Ambiental pode e deve ser utilizado como alternativa fundamental para lidar com os impactos antrópicos no mar e na efetivação de Políticas Ambientais Marinhas e Costeiras (PAMC).

Ações de abordagem sistêmica em escolas envolvendo a problemática do lixo no oceano já foram trabalhadas por educadores ambientais mostrando a importância do tema e a resposta de crianças do ensino fundamental, que de forma conjunta, buscaram soluções para o problema (BRUCK; FERREIRA; MACHADO, 2020).

O trabalho de Educação Ambiental em escolas, comunidades tradicionais, de pescadores, incluindo também eixos do comércio e as demais partes interessadas nos recursos do mar, são caminhos que devem ser estimulados pelo poder público através do fornecimento de recursos e condições para as práticas educativas (IMENIS BARRADAS, 2020; SAMPAIO; SANTOS, 2020). 
Estas questões, no contexto atual, em que o mundo todo enfrenta dificuldades graves em diversos setores em função da pandemia da Covid-19, repercutem gravemente nos ecossistemas marinhos e costeiros, como o aumento significativo de resíduos, especialmente o plástico, nestes ambientes (SILVA et al., 2020).

Estes materiais são uma ameaça à fauna marinha, podem comprometer atividades turísticas e de pesca, trazendo prejuízos para as comunidades locais que dependem dos recursos do mar. Além disso, podem provocar desequilíbrio ecossistêmico, o que destaca a importância de uma consciência ambiental e sensibilização para a problemática, buscando ações unificadas e solidárias (COSTA; DUARTE; ROCHA-SANTOS, 2019; SANTOS et al., 2020; SILVA et al., 2020).

Para mitigar estes impactos e colaborar para a eficácia das PAMC, sugere-se a aplicação de jogos, discussões, oficinas, debates, eventos e outros projetos à curto, médio e longo prazo, em diversos locais e distribuídos para diferentes públicos-alvo, considerando as especificidades de cada grupo social, suas fragilidades e disponibilidade para as atividades.

Frisa-se também, a relevância da interdisciplinaridade no desenvolvimento de quaisquer atividades de Educação Ambiental aplicadas aos ecossistemas marinhos e costeiros, respeitando e valorizando as diferentes formas do saber e incluindo diversidade cultural, religiosa e local. A Figura 2 representa um mapa com os principais assuntos, temas e disciplinas relevantes para trabalhar a Educação Ambiental na problemática oceânica.

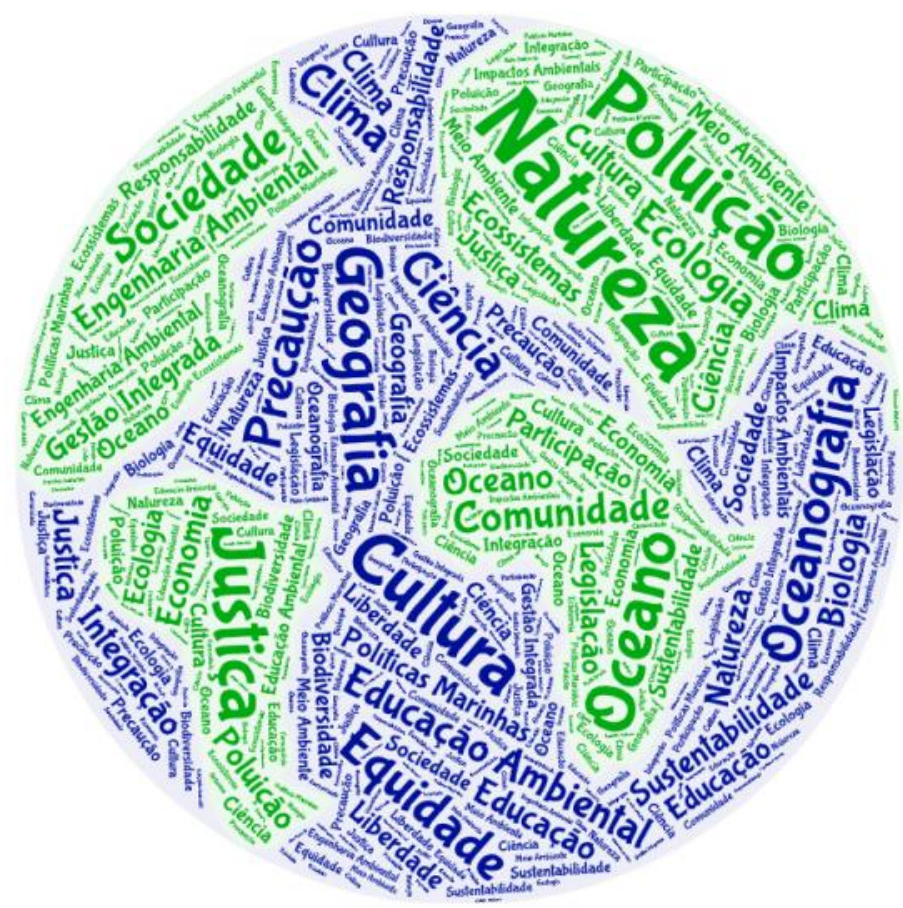

Figura 2: Nuvem da interdisciplinaridade entre alguns aspectos da Educação Ambiental e das Políticas Ambientais Marinhas e Costeiras (PAMC). Fonte: Dos autores. 
Além disso, é importante que estudos e pesquisas de acompanhamento sejam feitas, visando compreender a percepção ambiental popular sobre a problemática dos oceanos, incluindo as mudanças climáticas e aspectos correlacionados (PEDRINI et al., 2016).

Outro elemento fundamental é a compreensão dos impactos antrópicos no mar, suas causas e o papel social nesta dimensão. $O$ desenvolvimento deste conhecimento pode ser um instrumento fundamental para a Gestão Marinha e Costeira, visando a redução de impactos ambientais e a preservação dos recursos marinhos e costeiros, dos ecossistemas e da biodiversidade.

O Quadro 1 sugere opções de atividades de Educação Ambiental que podem ser utilizadas para a reflexão e o estímulo à adoção de práticas sustentáveis e quebra de paradigmas. Os questionamentos citados podem ser desdobrados gerando uma série de novas questões, enriquecendo o processo de aprendizado.

Quadro 1: Opções de atividades de Educação Ambiental.

\begin{tabular}{|c|c|c|}
\hline \multicolumn{3}{|c|}{$\begin{array}{l}\text { Práticas de Educação Ambiental aplicadas à problemática dos impactos antrópicos nos } \\
\text { ambientes marinhos e costeiros }\end{array}$} \\
\hline Prática/ Atividade & Objetivos/ Observações & $\begin{array}{l}\text { Questionamentos/ } \\
\text { Problemas-chave }\end{array}$ \\
\hline $\begin{array}{l}\text { Jogos interativos ou } \\
\text { individuais, virtuais ou } \\
\text { coletivos. }\end{array}$ & $\begin{array}{l}\text { Despertar, por meio lúdico, o } \\
\text { interesse pelo tema, aplicado } \\
\text { principalmente para o público jovem } \\
\text { e infantil. }\end{array}$ & \multirow{4}{*}{$\begin{array}{l}\text { "Quais são os impactos das } \\
\text { atividades humanas que são } \\
\text { mais evidentes no } \\
\text { mar?"..."Qual é a nossa } \\
\text { responsabilidade para a } \\
\text { conservação do mar?"... "Você } \\
\text { sabe a importância do oceano } \\
\text { na sua vida?"... "Quem são os } \\
\text { responsáveis pelo lixo no } \\
\text { mar?"... "Como podemos } \\
\text { contribuir para a melhoria do } \\
\text { ambiente marinho?"... "Que } \\
\text { práticas do seu dia-a-dia que } \\
\text { poderiam ser modificadas para } \\
\text { a sustentabilidade no } \\
\text { oceano?"..."O que são } \\
\text { ecossistemas costeiros e } \\
\text { marinhos?"... "O que dizem as } \\
\text { Políticas Ambientais Marinhas } \\
\text { e Costeiras?" }\end{array}$} \\
\hline $\begin{array}{l}\text { Cartilhas, livros, Gibis, } \\
\text { Apostilas, impressas ou } \\
\text { virtuais. }\end{array}$ & $\begin{array}{l}\text { Despertar o interesse pelo tema. } \\
\text { Abordagem mais aprofundada. Para } \\
\text { todos os tipos de público. Buscar } \\
\text { garantir fácil acesso. }\end{array}$ & \\
\hline $\begin{array}{c}\text { Reuniões, Debates, } \\
\text { Congressos, Seminários, } \\
\text { Conferências, Palestras e } \\
\text { afins. }\end{array}$ & $\begin{array}{l}\text { Atingir um público formador de } \\
\text { opinião, professores, gestores, } \\
\text { empresários e outros. Caráter mais } \\
\text { formal. }\end{array}$ & \\
\hline $\begin{array}{l}\text { Aulas, e processos } \\
\text { pedagógicos a médio e } \\
\text { longo prazo, contendo } \\
\text { monitoramento. }\end{array}$ & $\begin{array}{l}\text { Garantir o aprendizado contínuo e } \\
\text { duradouro. Acompanhar os } \\
\text { resultados do processo. Pode } \\
\text { contemplar as práticas anteriores. }\end{array}$ & \\
\hline
\end{tabular}

Fonte: Dos autores.

Frisa-se ainda que, a abordagem dos aspectos descritos no Quadro 1 devem ser trabalhados em harmonia com os principais princípios do Direito Ambiental, que se encontram hierarquicamente superiores a qualquer regra ou política (SILVA; FELícIO, 2017), de forma que o cidadão tenha consciência de 
seus direitos e deveres sobre os recursos ambientais que usufrui, direta ou indiretamente.

Dentre estes princípios destacam-se: a) do Desenvolvimento Sustentável; b) da Participação Comunitária ou Cidadã; c) da Precaução; d) da Prevenção; e) do Poluidor-Pagador; f) da Proibição do Retrocesso Ambiental; g) democrático; h) da responsabilidade (SILVA; FELÍCIO, 2017).

\section{Conclusões}

As Políticas Ambientais Marinhas e Costeiras (PAMC) são importantes para a preservação dos recursos do mar. Todavia, precisam de ferramentas da Educação Ambiental para a sua efetividade, especialmente na construção de uma nova cultura e de valores sociais comprometidos com a conservação dos recursos naturais e sustentabilidade.

Neste sentido, as práticas de Educação Ambiental, como as expressas no Quadro 1, são alternativas que podem contribuir para a efetividade das PAMC, uma vez que as ferramentas utilizadas podem ser adaptadas para diferentes realidades e tipos de público.

A importância de atividades de Educação Ambiental em escalas locais, regionais e globais é urgente e deve ser feita em todos os níveis de ensino, buscando atingir primeiramente os indivíduos com relações mais diretas com 0 oceano, seguido daquelas cujas ações implicam em impactos indiretos nestes ambientes.

Em um contexto global de crise emplacada pela pandemia provocada pelo novo coronavírus (SARS-CoV-2), a vulnerabilidade dos ecossistemas marinhos e costeiros é acentuada perante o aumento de resíduos, o que frisa um obstáculo presente e futuro a ser resolvido, ao qual a participação coletiva será essencial, o que demandará processos intensos de Educação Ambiental e incentivo do Estado.

A atenção comunitária pode resultar em conservação dos recursos naturais, assim como o seu abandono em impactos negativos e degradação ambiental. Desta forma, conclui-se que, no cenário atual, com a problemática da poluição marinha e costeira intensificada pela pandemia da Covid-19, devido ao aumento de resíduos, vinculada também ao negacionismo científico e propagação de informações falsas, o futuro representará um cenário em que o papel da Educação Ambiental será ainda mais importante.

\section{Agradecimentos}

Ao Programa de Pós-graduação de Ciências Ambientais (PPGCA) da Universidade Federal de Alfenas (UNIFAL-MG) e à Coordenação de Aperfeiçoamento de Pessoal de Nível Superior - Brasil (CAPES) - Código de Financiamento 001. 


\section{Referências}

ASLAN, J. F.; PINTO, A. E. M.; OLIVEIRA, M. M. Poluição do meio ambiente marinho: um breve panorama dos princípios, instrumentos jurídicos e legislação brasileira. Planeta Amazônia: Revista Internacional de Direito Ambiental e Políticas Públicas, n. 9, p. 175-186, 2017.

BARBOSA, J. A. A.; AGUIAR, J. O. Etnoconservação e história ambiental para um novo modelo conservacionista do século XXI Etnoconservation. Novos Cadernos NAEA, v. 21, n. 2, p. 243-255, 2018.

BEIRÃO, A. P. Política Marítima Nacional - atualidade e perspectivas. Rio de Janeiro. $3^{\circ}$ Fórum do Mar dos Países da CPLP, 2019.

BEZERRA, A. A. Fragmentos da História da Educação Ambiental (EA). Universidade Federal do Amazonas. Disponível em: $<$ http://www.cefort.ufam.edu.br/dialogica/files/no3/Vol03-01-

Fragmentos\%20da\%20historia\%20da\%20educaca0\%20ambiental.pdf >. Acesso em: 12 maio. 2021.

BRASIL. Lei no 6.938, de 31 de agosto de 1981. Disponível em: < http://www.planalto.gov.br/ccivil 03/leis/6938.htm>. Acesso em: 7 mar. 2021.

BRASIL. Lei no 7.661, de 16 de maio de 1988. Disponível em: <http://www.planalto.gov.br/ccivil 03/leis//7661.htm>. Acesso: 11 mai. 2021.

BRASIL. Decreto no 1.265, de 11 de outubro de 1994. Aprova a Política Marítima Nacional (PMN). Disponível em: $<$ http://www.planalto.gov.br/ccivil 03/decreto/1990-1994/D1265.htm>. Acesso em: 7 mar. 2021.

BRASIL. Decreto № 1530, de 22 de junho de 1995. Declara a entrada em vigor da Convenção das Nações Unidas sobre o Direito do Mar, concluída em Montego Bay, Jamaica, em 10 de dezembro de 1982. Disponível em: <http://www.planalto.gov.br/ccivil 03/decreto/1995/D1530.htm\#: :text=DECRE TO\%20N\%C2\%BA\%201.530\%2C\%20DE\%2022,10\%20de\%20dezembro\%20d e\%201982.>. Acesso em: 7 mar. 2021.

BRASIL. Lei no 9.795, de 27 de abril de 1999. Disponível em: < http://www.planalto.gov.br/ccivil 03/leis/19795.htm> Acesso: 11 mai. 2021.

BRASIL. Decreto no 5.377, de 23 de fevereiro de 2005. Aprova a Política Nacional para os Recursos do Mar - PNRM. Disponível em: $<$ http://www.planalto.gov.br/ccivil 03/ Ato20042006/2005/Decreto/D5377.htm>. Acesso em 11 mai. 2021.

BRUCK, S. C.; FERREIRA, G. K.; MACHADO, G. S. Conscientização ambiental de estudantes sobre o descarte correto de plásticos. $71^{\text {a }}$ Reunião Anual da SBPC. Anais...2020.

BUEGER, C. What is maritime security? Marine Policy, v. 53, p. 159-164, 2015. 
COSTA, J. P. DA; DUARTE, A. C.; ROCHA-SANTOS, T. Plásticos no ambiente. Revista Recursos Hídricos, v. 40, n. 1, p. 11-18, 2019.

COSTANZA, R. The ecological, economic, and social importance of the oceans. Ecological Economics, v. 31, p. 199-213, 1999.

DE OLIVEIRA, N. R.; DOS SANTOS, C. R.; TURRA, A. Environmental perception as support for coastal management in the bay of araçá, northern coast of the são paulo state, Brazil. Desenvolvimento e Meio Ambiente, v. 44, p. 140-163, 2018..

FIALHO, R. G. M.; CUNHA, E. V. DA. Sustentabilidade e afeto: a dimensão afetiva da sustentabilidade na família. Revista Brasileira de Educação Ambiental, v. 13, n. 4, p. 313-333, 2018.

FRANCESCHI, F. R. A. DE et al. Panorama dos resíduos sólidos no Brasil: uma discussão sobre a evolução dos dados no período 2003 2014. Revista DAE, v. 65, n. 206, p. 62-68, 2017.

GARCIA, M. A. et al. Duas décadas da PNEA: Avanços e Retrocessos no Brasil. Revista Brasileira de Educação Ambiental, v. 15, n. 5, p. 250-270, 2020.

HATJE, V.; DA CUNHA, L. C.; DA COSTA, M. F. Oceanography and chemistry: bridging knowledge in favor of the oceans and society. Quimica Nova, v. 36, n. 10, p. 1497-1508, 2013.

HATJE, V.; DA CUNHA, L. C.; DA COSTA, M. F. Global changes, anthropogenic impacts and the future of the oceans. Revista Virtual de Quimica, v. 10, n. 6, p. 1947-1967, 2018.

IMENIS BARRADAS, J. Os Oceanos Como Instrumento De Educação Ambiental. Revista de Ensino de Ciências e Matemática, v. 11, n. 2, p. 2433, 2020.

LAYRARGUES, P. P. Pandemias, colapso climático, antiecologismo: Educação Ambiental entre as emergências de um ecocídio apocalíptico. Revista Brasileira de Educação Ambiental, v. 15, n. 4, p. 1-30, 2020.

MATIAS, T. P.; IMPERADOR, A. M. Overview of sea conservation policies in Brazil and social and environmental impacts in the context of the Covid-19 pandemic. Research, Society and Development, v. 10, n. 12, p. e451101220786, 26 set. 2021.

MOREIRA, F. C. Políticas Públicas Para o Ambiente Marinho e Seus Recursos. e-Pública: Revista Eletrónica de Direito Público, v. 7, n. 2, p. 27-54, 2020.

PEDRINI, A. DE G. et al. Percepção ambiental sobre as mudanças climáticas globais numa praça pública na cidade do Rio de Janeiro (RJ, Brasil) TT. Ciênc. Educ., v. 22, n. 4, p. 1027-1044, 2016. 
PEREIRA, A. S. et al. Método Qualitativo, Quantitativo ou Quali-Quanti. 1. ed. Santa Maria RS: UFSM, NTE, 2018. Disponível em: $<$ https://www.ufsm.br/app/uploads/sites/358/2019/02/Metodologia-da-PesquisaCientifica final.pdf> Acesso: 12 mai. 2021.

RIBEIRO, E. M. et al. Unidades de Conservação costeiras e marinhas no Brasil. In: MUEHE, D.; LINS-DEBARROS, F. M.; PINHEIRO, L. (orgs.) Geografia Marinha: oceanos e costas na perspectiva de geógrafos. Rio de Janeiro: PGGM, 2020. p. 402-437. ISBN 978-65-992571-0-0. Disponível em $<$ https://www.researchgate.net/profile/Dieter-

Muehe/publication/345768862 livro Geografia Marinha PGGM ABEQUA 20 20/links/5fad49e245851507810d5f30/livro-Geografia-Marinha-PGGM-

ABEQUA-2020.pdf> Acesso: 12 mai. 2021.

RIO, G. P. DO. Mares e oceanos: novas fronteiras da regulação territorial? Revista Brasileira de Geografia, v. 63, n. 1, p. 61-72, 2018.

SAMPAIO, C. P. DE; SANTOS, A. DOS. A contribuição do pensamento de sistemas para a Educação Ambiental: teoria, metodologias, métodos e ferramentas. Revista Brasileira de Educação Ambiental, v. 15, n. 7, p. 334347, 2020.

SANTOS, T. DOS et al. First record of microplastics in two freshwater fish species (Iheringhthys labrosus and Astyanax lacustris) from the middle section of the Uruguay River, Brazil. Acta Limnologica Brasiliensia, v. 32, n. e26, p. 1-6, 2020.

SILVA, A. L. P. et al. Increased plastic pollution due to Covid-19 pandemic: Challenges and recommendations. Chemical Enginnering Journal, v. 405, n. 2021, p. 126683, 2020.

SILVA, A. R. DA; CHAVES, G. D. L. D.; GHISOLFI, V. Os Obstáculos Para Uma Efetiva Política De Gestão Dos Resíduos Sólidos No Brasil. Veredas do Direito: Direito Ambiental e Desenvolvimento Sustentável, v. 13, n. 26, p. 211, 2016.

SILVA, F. L. P.; FELÍ́CIO, M. J. Os Princípios Gerais do Direito Ambiental. Colloquium Socialis, v. 1, n. Especial, p. 632-640, 2017.

SONG, A. M. Human dignity: A fundamental guiding value for a human rights approach to fisheries? Marine Policy, v. 61, p. 164-170, 2015.

TELLES, D. H. Q. Territorial approach to Marine Geography: Preliminary reflections since the spatial planning and integrated governance. Desenvolvimento e Meio Ambiente, v. 49, p. 336-354, 2018.

TRAJANO, E. Políticas De Conservação E Critérios Ambientais: princípios, conceitos e protocolos. Estudos Avançados, v. 24, n. 68, p. 135-146, 2010.

VALÉRO, G. A.; SANTIAGO, K. DE L. A.; FRANÇA, R. DE L. V. ASPECTOS DA REVOLUÇÃO INDUSTRIAL NA ECONOMIA GEO-HISTÓRICA MUNDIAL. Revista de Teologia da Faculdade FASSEB, v. 9, n. 1, p. 1689-1699, 2019. 